\title{
Preventing repeat incidents of family violence: analysis of data from three field experiments
}

\author{
ROBERT C. DAVIS \\ Police Foundation, 1201 Connecticut Avenue, NW, Washington, D.C., 20036-2636, USA \\ E-mail:rdavis@policefoundation.org
}

CHRISTOPHER D. MAXWELL

Michigan State University, East Lansing, Michigan, USA

The University of Michigan, Ann Arbor, Michigan, USA

BRUCE TAYLOR

Police Executive Research Forum, Washington, D.C., USA

\begin{abstract}
Preventing repeat victimization is an area of criminology that has shown particular promise in recent years. Based on the premise that persons once victimized are at higher risk than others for future victimization, British officials developed successful programs that focus crime prevention efforts on victims. Of all crimes, family violence may have the highest repeat rate, especially in the first weeks after an incident is reported to the police. Accordingly, New York City officials developed an intervention program to reduce repeat incidents of family abuse. Three field experiments conducted during the 1990s evaluated whether or not this program, targeted at public housing residents who reported family violence to the police, reduced the rate of subsequent victimization. The findings produced within each study were not consistent across the studies; rather, these three experiments, separately analyzed, produce varying results. Since the composition of the samples varied across studies, however, one possible explanation is that this program has different effects within different populations. This paper reports outcomes from a series of analyses of pooled data from these three studies to address the inconsistencies. The results indicate that the intervention brought about greater reporting of subsequent abuse, both to authorities and to research interviewers. The results are invariant across the three studies, indicating that greater reporting of abuse is not idiosyncratic to one particular population, and are consistent across the nature and source of outcome measures. These findings suggest the need for careful monitoring by the advocates and agencies that operate these types of programs and among those designing and testing future programs.
\end{abstract}

Key words: elder abuse, evaluations, intimate partner violence, repeat victimization

One of the most promising areas of research in criminology is the understanding and reducing of repeat victimization. For the past 30 years, victimization surveys have noted that a small percentage of the population experiences a relatively large proportion of all crime, and that one of the strongest predictors of victimization that researchers have isolated is being a victim on an earlier occasion (e.g., Hindelang et al. 1978; Sorenson et al. 1991). Reports by the Canada Solicitor General (1988), the National Board for Crime Prevention (1994), and others, have 
shown that sexual assault survivors have a substantially greater chance of revictimization than non-victims (see Banyard et al. 2002; Collins 1998; Gabor and Mata 2004; Gold et al. 1999; Messman-Moore and Long, 2000; Muehlenhard et al. 1998), robbery victims a nine-times greater chance, and residential burglary victims a four-times greater risk (Budd 1999; Bowers et al. 1998; Robinson 1998). Even many commercial thefts target the same premises victimized within the past 30 days (Whitehead and Gray 1998).

Because of the strong relationship between past and future victimization, many officials in both Britain and the United States of America developed a variety of programs to attenuate this linkage. This paper reports the results from analysis of data collected to test one such program specifically implemented to break the cycle among family violence victims. The paper utilizes a sample of nearly 1,000 cases pooled from three randomized experiments. While the tested treatments and research designs were nearly identical across the studies, there was variation across the studies in the composition of the sampling frames. First, variation existed in terms of the nature of victim-perpetrator relationships (one study was evenly split among intimate and non-intimate family members, one was predominately nonintimate with older victims, and one was predominately intimate partners). Second, two of the studies included a higher percentage of minor incidents (many not rising to the level of crimes), whereas the third study included more assaults and other criminal incidents. While this diversity in sampling creates a more complex analytic task, it also enhances the generalizability of the findings - if, of course, the results produced with similar measures and models remain constant across three dissimilar studies (Hall et al. 1994).

The sections that follow provide a review of the literature on repeat victimization and crime prevention programming, and provide background on the individual studies conducted in New York City that form the basis for our pooled multi-site analyses. Following this background material, we present the methods used in our study, followed by the results and discussion sections.

\section{Literature review}

Prior research has found that the risk of revictimization is greatest in the period soon after the previous victimization for crimes as diverse as school crime, residential burglary, bias crime, family violence, automobile crimes, neighbor disputes, and retail crimes (Farrell and Pease 1993; Shaw and Pease 2000). These studies provide some support for the concept of event dependency in repeat victimization (Sparks 1981; Ellingworth et al. 1995; Lauritsen and Davis-Quinet 1995): that is, there is something about a victimization that increases the risk of additional victimization.

In a number of ways, the British have led the way in capitalizing on the practical implications of repeat victimization. The study by Farrell et al. (2000) of British policing found that all police forces surveyed had a repeat victimization strategy, and Litton (2000) reports that the British insurance industry has 
recognized the significance of repeat victimization by motivating their clients and developing crime prevention programs. This approach is an efficient use of resources: "By pointing to the most probable times and places of future offenses, repeat victimization also helps identify the times and places where offenders may be found and apprehended (Farrell and Pease 1993). There is potential for the development of a symbiotic relationship between crime prevention and offender detection..." (National Board for Crime Prevention 1994, p. 2). The British also recognize that programs incorporating a problem-solving approach to policing should pay special attention to repeat victims, who contribute disproportionately to an area's crime statistics, especially in high-crime areas (Trickett et al. 1992).

In their work on repeat victimization (see Anderson et al. 1995; Farrell and Pease 1993), British officials have pursued a model of interaction between research and practice (for a summary see Farrell 1995, p. 19). In crimes ranging from burglary to family violence to racial violence, researchers have forged alliances with law enforcement authorities to define problems and assess the results of interventions (Pease 1998; Pease and Laycock 1996; Farrell 1995, p. 19). This model also calls for early intervention, since victims are more likely to accept crime prevention efforts immediately following victimization. There is a "window of opportunity" during the first weeks after a crime, during which victims feel vulnerable and are willing to consider serious behavioral and lifestyle changes (Davis and Smith 1994a).

In one intimate-partner violence-reduction project, victims received wearable alarms linked to the police by cellular phone, responding officers received en route information on prior calls and on current court orders, victim service workers offered support and developed an action plan with the victim, and lecture and discussion sessions were held with the police to raise their awareness of the issue of domestic violence and the police role. Evidence from victim interviews indicated that the pendant alarms greatly increased the recipients' sense of security (Lloyd et al. 1994). Research conducted on British multidisciplinary programs to reduce repeat domestic violence also suggested that they are effective in reducing additional calls to the police (Kelly et al. 1999; Farrell and Buckley 1999), although the evaluation designs were weak.

In the United States of America, researchers and public officials have also recognized the potential benefits of working with victims. A National Research Council conference on crime prevention featured a panel on repeat victimization and the United State Department of Justice Department's Office for Victims of Crime included repeat victimization in its national evaluation plan. Earlier, Davis and Smith (1994a) reported the results of a field test of a crime prevention program administered to recent victims. Davis and Smith (1994a) divided 191 victims of robbery, burglary, and non-sexual assault into two groups, using a quasiexperimental design. One group received traditional crisis counseling, while the other received instruction in crime prevention and was offered free upgrades of home security hardware. Relative to the crisis-counseling group, victims assigned to the crime prevention training had a $33 \%$ lower rate of revictimization than controls over the next 12 months. However, the sample was small and the 
difference only attained marginal statistical significance. The Police Executive Research Forum also conducted an extensive examination and field test in three cities of a program to reduce repeat burglaries (Weisel et al. 1999). Weisel et al. (1999) found that reported residential burglaries declined in the experimental areas receiving a police problem-solving approach relative to the comparison areas in two of the three sites.

\section{The New York City experiments}

Repeat victimization is a relatively rare phenomenon in some populations (e.g., Shaw and Pease 2000) and more common in others (e.g., Menard 2000). In households that make family violence reports to the police, the chance is quite high that there are subsequent and potentially more severe incidents. For instance, a 1977 Police Foundation study found that police had been called to the location of an assault or homicide at least once before in about $85 \%$ of the incidents and at least five times in 50\% of the cases (Wilt et al. 1977). Research derived from clinical samples has likewise shown that family violence escalates in frequency and severity (Pagelow 1981). Walker's (1979, p. 55) influential study of victims of intimate partner violence, for example, describes a "cycle of violence" that can occur hundreds of times, with periods lasting as short as an hour to over a year. Furthermore, the risk of revictimization by a partner is relatively immediate: Lloyd et al. (1994) found that the likelihood of a new incident is highest during the first 11 days following the initial incident. Accordingly, it is now conventional wisdom that family violence escalates in frequency and severity (Laub and Sampson 2001, 28).

One of the earliest American programs that addressed this link between past and future family violence by working with victims started in New York City in the mid-1980s. The New York City Housing Police Department and Victim Services (now Safe Horizon) started the Domestic Violence Intervention Education Project (DVIEP) as a response to repeat family violence. This program posited that repeat victimization would decline as victims extracted themselves from self-defeating relationships or by working with social services and criminal justice staff to develop strategies to end the abuse while staying in the relationship. Accordingly, the model called for a crisis response team, each consisting of a police officer and a social worker, to follow-up the initial police response to the complaint. The team provided the victim with information on services and legal options and warned those perpetrators present at the follow-up of the legal consequences of continued abuse. The interventions in this context, therefore, emphasized the application of legal remedies as well as the use of the social services designed to provide relief to the victims. The central aim of threatening legal remedies is to deter batterers from further abusing their intimate partners. This is accomplished by teaching them that assaulting an intimate is criminal and will cost them if they continue hitting their partners. At the same time, the purpose of working directly with the victims is to empower them by increasing their knowledge about their rights and available services and legal options. In turn, empowered victims should be emboldened to terminate untenable relationships or to work to end the battering within the context 
of the relationship. Thus, this two-pronged intervention was justified on the basis of its ability to break the "cycle of violence" among family violence victims.

DVIEP is an early example of the now-popular coordinated approaches to family violence interventions that focus on both abusers and victims. Advocates have argued that such approaches hold the best hope of reducing recidivism in households experiencing family violence (Hart 1992). Elements of the empowerment approach developed in New York are replicated in both England and in the United States of America. For example, the English program discussed earlier offered victims wearable alarms linked to the police, access to counseling by victim caseworkers, and community meetings designed to raise awareness of family violence and the police role (Lloyd et al. 1994). In the United States of America, a program in DuPage County, Illinois, combined a tough law enforcement approach to family violence with advocacy for the victims of violence. The advocates offer support, give women information about the legal system, and inform them about further counseling and advocacy services that are available (Tolman and Weisz 1995). Other similar programs have become common enhancements to the police patrol response to family violence (e.g., Lane et al. 2002). The availability of funds under the Violence Against Women Act and the stipulation that jurisdictions develop a coordinated response to family violence have further encouraged the promotion of the New York model across the United States, especially in its use of advocates who are summoned to victims' homes by the police to provide crisis counseling. However, some of the experimental data from New York City suggests that these interventions may have the opposite effect, while another evaluation suggests that a similarly designed program had no effect (Weisz et al. 2004, NCJ 199718).

The early efforts to evaluate the effectiveness of the DVIEP model in reducing repeat instances of family violence were inconclusive. However, like the earlier British studies, these evaluations used weak designs. Therefore, administrators decided to engage in a series of rigorously designed studies to determine the effectiveness of the DVIEP model. Between 1987 and 1997, our team conducted three field experiments in New York City's public housing projects. All three tested the same intervention model: persons who reported family violence to the police were randomly assigned to receive or not to receive a follow-up visit from a domestic violence prevention police officer and a social worker (Davis and Taylor 1997; Davis et al. 2000).

The sampling frame for the DVIEP experiment was households in designated public housing units in Manhattan where someone had called the police in response to a family violence incident (this could be violence between romantic intimates, siblings, adult child and parents, or other forms of violence between persons related or living under the same roof). The incidents were minor in nature, many not involving violations of criminal statutes: only $7 \%$ of the incidents resulted in arrests, and just $14 \%$ of victims reported any form of injury. Four hundred thirty-five victims were randomly assigned to receive a home visit as a follow-up to the patrol response. The control group received only the initial police patrol response. The research team tracked both groups for additional calls for police services over the next 6 months. 
At the end of the tracking period, researchers attempted to interview victims to ask about new abuse, about satisfaction with the police response, and about the victims' knowledge and use of social services. The research team completed interviews with $72 \%$ of the sample. This relatively high success rate for a family violence criminal justice sample was due in part to the low level of transience among New Yorkers living in public housing (Davis and Taylor 1997).

Based on law enforcement records, households receiving the home visit or public education intervention were more likely to call the police within 6 months than were those not receiving the interventions. Yet, according to victim survey data, there were no differences between the two groups in abuse during the 6 months following the trigger incident. In the literature on the effectiveness of arrest on curbing violence, researchers usually consider victim reports and calls to the police as imperfect indicators measuring an underlying construct of actual violence. However, the two measures clearly are not synonymous. Many victimizations - and, especially, many family violence victimizations - are not reported to the police (Straus and Gelles 1990; Harris and Associates 1979; Dutton 1995). Davis and Taylor (1997) interpreted this pattern of results to mean that the experimental interventions did not affect actual violence levels but did increase victims' confidence in the police and their willingness to report violence when it occurred. Indeed, that explanation is consistent with the theory on which DVIEP was based: Program administrators hoped that victims who received the intervention would call the police more often because they would gain confidence that the police would help.

Davis and Medina (2001) conducted a second experiment to test the same interventions several years later; this time using a sample of public housing residents who had reported elder abuse incidents to the police. Like the cases in the first field test, incidents in this study (hereafter referred to as the "elder abuse" study) were relatively minor. Five percent of the abusers were arrested, just $4 \%$ of victims reported any injuries, and only $22 \%$ of the incidents involved a crime allegation (the remainder were labeled by the police as verbal or family disputes). Once again, the researchers tracked law enforcement records for the next 6 months. As in the first experiment, Davis and Medina (2001) interviewed more than $70 \%$ of victims in the sample at the end of the 6-month tracking period. Also as in the first experiment, Davis and Medina (2001) found that victims who received the home visit intervention called the police sooner and more often than controls. However, unlike the earlier study, there were no differences between households assigned to the home visit condition and those not. Survey results showed that victims who received both home visits and public education were significantly more likely to report new abuse than were those who received neither home visits nor public education.

Taylor and Davis also conducted a third (unpublished) experiment (hereafter referred to as the PSA2 study), this time analyzing only the home visit intervention (leaving out a public education treatment). This test, also conducted in a public housing setting, involved 197 family violence victims. While the earlier two studies selected all incidents reported to the police, regardless of the nature of the criminal justice intervention, this third field test relied on cases that only involved an arrest. 
Twenty-two percent of abusers were charged with felonies, and the remainder with misdemeanors or technical violations (the modal charge was third-degree assault). One in five of the victims reported some injury. They collected similar data to those from the other two experiments - new incidents reported on surveys or reported to law enforcement agencies -6 months after the trigger incident. The analyses of data from this third study are reported in Davis and Maxwell (2002). ${ }^{1}$

\section{Synthesizing the findings}

The first two studies in this series were consistent in the finding that households assigned to receive a home visit called the police more frequently over the next 6 months than did households that were assigned to a control condition. In the first study the same was true for households assigned to the public education condition. In this initial study, where differences in violence reported on victim surveys was not found, the results seemed to indicate that the interventions did not affect actual abuse but encouraged victims to call the police when abuse occurred. However, in the second study, those who had received both interventions reported more violence to the police and more violence on victim surveys. These findings are more troubling then those from the first test. Since victim surveys are widely accepted as an indication of true incident rates, these results suggest that the interventions may have increased violence, not just the reporting of violence. However, there were differences between the studies, most notably in terms of age and nature of victim/offender relationship, that may account for the different results. The victims in the second study may have been involved in a more dependent relationship with the abuser, making leaving a less likely option. If abusers of older relatives become angered by attempts to intervene, there may be no good escape for the victim. Preliminary bivariate analysis of data from the third study found results that fell between the other two studies: there was no significant differences between home visit and control conditions on either official reports of new abuse or abuse reported to research interviewers (Davis and Maxwell 2002).

The pooled data analysis presented in this paper was conducted in an effort to identify whether these within-site results were consistent across the three studies or whether the treatments significantly varied by site. We believed that, if we could identify conclusions that held across the three experiments, we would produce consistent information that would inform policy makers of the potential dangers involved in deploying this intervention approach.

\section{Methodology}

Often, researchers need to rely on traditional meta-analytic techniques to synthesize the results from a series of experiments, frequently because they do not have access to the micro-data for each study (Blettner et al. 1999). But when micro-data are available, the justification for pooling data rather then performing a meta-analyses includes the fact that the former method can provide improved and 
fewer bias point estimates (Blettner et al. 1999; Breipohl et al. 1995; Taioli and Bonassi 2002), afford more statistical power (Taioli and Bonassi 2002), present the option for standardizing the case selection criteria and covariates (Blettner et al. 1999), and create the possibility of specifying more interactions and sub-group tests to evaluate the degree of between-group heterogeneity (Taioli and Bonassi 2002) For this paper we are fortunate to have access to the micro-data and variables that are comparable across the studies and, therefore, have chosen to conduct a series of analysis of the pooled micro-data from the three experiments.

Besides the methodological justification, we believe that pooling data from these three experiments is substantively reasonable because the context and the programmatic protocols for the three studies are the same: all experiments were set in New York City public housing; all tested a program model developed by the New York Police Department (NYPD) and Safe Horizon; all recruited cases in the same way (through households that filed complaints with the NYPD); all used a similar method of assigning cases to treatments, and all used the same data sources and similar measurement protocols. However, there are also several design differences, including the type of abuser (two studies targeted cases that primarily involved aggression between intimate partners, while the other focused on aggression against an elder family member) and the seriousness of the offenses (two studies involved any incident results in a call to the police, while one selected only incident results in an arrest), that some might argue could prevent valid comparison using the pooled micro-data. ${ }^{2}$ Conversely, we believe that this dissimilarity in samples is a strength of this work. If the estimated effects following pooling are clear-cut, and if the specified site by treatment interaction terms are not significant, then the results from this work are more robust and generalizable across different family violence populations. Moreover, the same objection could be raised about any meta-analysis study, which can combine studies that are more disparate in method and population than the ones combined here but cannot address, as we can, the imbalances in the sample characteristics by controlling for other measured covariates. We therefore concatenated the microdata from the three experiments into a single file that contain identical treatment and control measures, and nearly identical outcome measures. The new database has information on 1,037 cases and 675 6-month victim interviews (a 65\% followup success rate). The sections below describe the program model that was the target of the evaluations, the process of creating comparable measures across the datasets, and the analysis strategy.

\section{The treatment model}

Home visit intervention. For designated incidents, a team consisting of a social worker and a police officer visited households within a few days of a domestic complaint. The visits generally lasted 10-30 minutes, depending on whether the batterer was present and on the victim's receptiveness to assistance. During that time victims were informed about services and about pursuing legal remedies, especially obtaining restraining orders. Referrals were made, most commonly to 
counseling services and support groups, drug and alcohol treatment programs for batterers, battered women shelters, home security improvement services, health care assessment and assistance, emergency financial assistance, assistance with relocating to other public housing units, and respite assistance for caregivers who batter seniors. On-the-spot crisis counseling was provided when indicated. [Details on the home visits are available in Davis and Medina (2001) and Davis and Taylor (1997)]. This visit intervention was somewhat stronger than that normally delivered by DVIEP, which often consisted of either a telephone call or a letter. Researchers and administrators decided to use the "gold standard" programmatic response in the evaluation studies.

In cases where the complainant was not home in two tries, literature was left and/ or telephone contact made with the household. Contact was made with the household in $69 \%$ of cases in the DVIEP study and in $84 \%$ of the cases in the elder abuse study. (No information on outcomes of home visit attempts is available for the PSA2 study.) While it might be argued that this reduces the internal validity of the studies, we and other evaluators [Davis and Smith (1994b) and Gartin (1995)] have argued that the fact that an intended criminal justice intervention is not always actually delivered does not reflect a weakness in the experiment. The test was of a public policy intervention - a program to make reasonable efforts to conduct follow-up home visits within time and budgetary constraints. Only in a perfect world would every household have received the intended follow-up visit. Researching such a system might tell us about whether home visits work in theory but would not inform us about a public policy which attempts to conduct home visits.

\section{Public education intervention}

In the first two field experiments there was also a second experimental treatment. The public housing units included in the studies were randomly assigned to receive or not receive education about family violence, through brochures, posters, and public meetings. With cooperation of housing authority staff, leaflets were delivered to the door of every apartment in housing projects assigned to the public education treatment. Posters and additional leaflets were placed in common areas, such as around mailboxes and in housing managers' offices. The leaflets contained information on the legal rights of victims, locations of emergency and long-term services, and the importance of the police in ending family violence. Presentations at community meetings were designed to familiarize housing project residents with the family violence team in the local Housing Police precinct and to educate the community about the nature of family violence.

\section{Measures}

We constructed outcome measures based on criminal justice information sources and victim interviews for each data set (see Table 1). From criminal justice sources, each of the three databases contained information about subsequent 
incidents of family violence reported by the sampled households within 6 months of the trigger incident. This information was used to calculate measures of prevalence and count of the number of new calls for police services within 6 months following the trigger incident, and the time between the trigger incident and the first new incident of reported abuse.

In the DVIEP and PSA2 studies, victims were queried about the frequency and severity of violence in the past 6 months with the widely used Conflict Tactic Scale (CTS) (Straus 1979). The scale includes the number of times victims were assaulted with a weapon; threatened with a weapon; hit, kicked, or shoved; had property damaged, or were harassed. Under the scoring system recommended by Straus (1979), weapon assaults incidences were given weights of 8, followed by weapon threats (6), and hits, kicks or shoves (2). The remaining items received a weight of 1 . In the elder abuse study, we used a variant of the CTS adapted by Pillemer and Finkelhor (1998) that included measures of physical, psychological, and financial abuse. The great majority of abusive incidents were minor in nature. Nearly all that resulted in injuries involved, at most, cuts or abrasions not requiring professional medical treatment. From these abuse questions we developed a measure of the proportion of victims reporting any new abuse and a measure of the frequency/intensity of abuse.

All three experiments also used similar versions of questions about victims' use of social services (including legal assistance, victim services, church groups, courts, shelters, and support groups) that generated counts of the number of services used, from 0 to 6 . The three datasets also had available comparably coded information on victims' ages and involvement in a romantic relationship with the abuser (see Table 1). For a number of reasons, we included these demographic variables as covariates in our pooled analysis, even though we were relying on an experimental design. First, the addition of several covariates such as site and age can prevent the generation of a Simpson's paradox, a problem several reviewers of pooled data have identified as an issue with pooled analysis (Bravata and Olkin 2001). Second, statistical controls for other factors can improve the precision of the treatment comparisons by correcting for any imbalance in the distribution of these measures across treatments that may have occurred by chance or because we pooled data across studies (Angrist 2005; Angrist and Hahn 2004; Armitage 1996, vol. 13, p. 13; Taioli and Bonassi 2002). Third, since the cases assigned randomly to the same treatment group are not alike, the addition of statistical controls can address the natural variations between suspects within each treatment group (Gelber and Zelen 1986). Fourth, while an experimental analysis typically tests for only the average effect of a treatment across all subjects, whatever their characteristics, the addition of relevant covariates provides an opportunity to test non-experimental hypotheses, such as whether age is also related to the outcomes, and how treatment effects may vary across other dimensions of other uncontrolled extraneous factors, such as study, marital status, employment level or prior criminal records. Finally, Gelber and Zelen (1986) argue that experimental results are more credible if important extraneous factors are controlled. Thus, while it is possible that a covariate may be so highly correlated with the assigned treatment to 
cause multicollinearity problems, this possibility was tested for and not found, and therefore, their inclusion outweighed this single cost, particularly in our pooled data analysis.

\section{Analytical models}

The basic measure we used to analyze effects of treatments upon recidivism was the proportion of cases in which new abusive incidents were reported to the police or to research interviewers. These data were analyzed using logistic regression models. In addition to learning whether the interventions affected the proportion of households reporting a new abusive incident, we also wanted to know whether the interventions changed the frequency or intensity of incidents. We therefore also modeled the count of new abusive incidents, because it has been argued that the prevalence of an event may not be a good yardstick for understanding the impact of a social intervention and, in particular, criminal justice sanctions (Farrington 1987, vol. III). Because both the arrest counts and the CTS measure produces a skewed distribution (most cases have no repeat incidents, while a few have many and severe repeats) with overdispersion, we used negative binomial regression models. These models were developed to address distributions where the majority of the sample does not fail at all during the time observed, while only a handful failed more often. We likewise used the negative binomial model to regress the use of services, because this measure is also a count measure with a similarly negatively skewed distribution.

We were also interested in knowing whether the interventions affected the time to the first new incident of abuse following the trigger incident. Accordingly, we used a Cox semi-parametric regression model to compare differences between treatment conditions in terms of hazard rates. Our model introduces independent variables representing treatment designations and study (first, second, or third) in order to estimate whether the baseline hazard function is dependent on the level of each independent measure.

The first and second studies each used a factorial design, with home visits and public education as treatments. In the third study the home visit was the single independent variable. Therefore, our primary analysis was with data from the first two studies, to determine whether the two factors separately or in concert affected recidivism and service utilization. Following presentation of the results of the twostudy analysis, we present the more limited analyses that examine the effects of home visits based on data from all three studies. For analysis of all outcome measures using the various techniques described above, we included terms representing the two experimental treatments and designation of which of the three studies each case came from. We also included nature of victim/offender relationship and victim's age as covariates. Each table reporting multivariate results contains two statistical models - the first with only main effects and the second with main effects and terms representing interactions between treatments. 
Table 1. Comparison of key measures by studies.

\begin{tabular}{|c|c|c|c|}
\hline & Study 1:domestic violence & Study 2:elder abuse & Study 3: PSA2 \\
\hline Parameter & $(n=434)$ & $(n=406)$ & $(n=197)$ \\
\hline \multicolumn{4}{|l|}{ Demographics } \\
\hline $\begin{array}{l}\text { Percentageof romantic } \\
\text { relationship }\end{array}$ & $42 \%$ & $19 \%$ & $69 \%$ \\
\hline Mean age (years) & 39 & 66 & 32 \\
\hline \multicolumn{4}{|l|}{ Abuse reports to police } \\
\hline $\begin{array}{l}\text { Percentageof new report } \\
\text { to police }\end{array}$ & $38 \%$ & $33 \%$ & $23 \%$ \\
\hline $\begin{array}{l}\text { Mean no. of new reports } \\
\text { to police }\end{array}$ & 0.86 & 0.61 & 0.32 \\
\hline $\begin{array}{l}\text { Mean no. of days to first } \\
\text { new abuse }\end{array}$ & 50.4 & 63.5 & 92.1 \\
\hline \multicolumn{4}{|l|}{ Abuse reports on survey } \\
\hline $\begin{array}{l}\text { Percentage of new report } \\
\text { on survey }\end{array}$ & $43 \%$ & $34 \%$ & $28 \%$ \\
\hline $\begin{array}{l}\text { Mean frequency/severity } \\
\text { score }\end{array}$ & 7.19 & 6.85 & N/A \\
\hline Mean no. of services used & 2.3 & 0.7 & 1.8 \\
\hline
\end{tabular}

\section{Results}

The purpose of conducting a randomized experiment is to assess the unmitigated effects of an intervention by comparing a group that receives treatment with an equivalent group who do not receive it. This design produces a compelling counterfactual describing what would have happened to the treatment group if they had not been exposed to the treatment (Rubin 1974; Holland 1986). To assess whether we were able to create such equivalent conditions (i.e., the groups were equivalent in all relevant ways except for the assignment of treatment), we began our analyses by comparing case characteristics between the experimental and treatment groups for each of the three studies.

In the DVIEP study, there were no significant differences between those assigned to public education or control in terms of victim and perpetrator age or gender; relationship between victim and perpetrator; prior arrests and complaints; and length of relationship. There were no significant differences between those who were and were not assigned to receive home visits based on victim or perpetrator age; relationship; victim gender; prior arrests and complaints; and length of relationship. There were significant differences between those assigned and not assigned to home visits based on perpetrator gender $(25 \%$ of home visit perpetrators were female compared with $16 \%$ of controls). In the elder abuse study, experimental and control groups did not differ on victim injury; victim and perpetrator age; victim gender; perpetrator race; relationship between victim and 
perpetrator; and existence of an order of protection against the abuser. There were significant differences at the 0.05 level in terms of victim race $(37 \%$ of victims in the home visit group were Hispanic versus $26 \%$ in the control group) and perpetrator gender $(71 \%$ of perpetrators in the home visit group were male compared with $62 \%$ of control perpetrators). In the PSA2 study, we found no significant differences between those assigned and not assigned to receive a home visit in terms of victim age and education; previous complaints filed with the police; nature of relationship between victim and perpetrator; and charge class (felony or misdemeanor).

The above results suggest that the treatment and control groups for each of three studies were generally very similar prior to the introduction of the intervention. However, with the DVIEP study, we found that there were small (but statistically significant) differences for those assigned and not assigned home visits based on perpetrator gender. In addition, similar small demographic differences were uncovered for the elder abuse study based on victim race and perpetrator gender for those assigned to the home visit group compared with those not assigned. While statistically significant, none of these differences appears to be substantively important. We arrived at this conclusion when we added these variables (perpetrator gender and victim race) to our substantive models (Tables 3, 4, 5, 6, and 7) and found no changes in those models (we do not present these data runs in this paper). These data suggest that the use of random assignment functioned as planned and produced pre-treatment similarity/equivalence between the treatment and control groups.

\section{Two-study recidivism results}

Tables 2, 3, and 4 consider the direct and interactive effects of offering follow-up home visits and a public education program, based on the DVIEP and elder abuse studies that included both these treatments. Table 2 summarizes the new abuse measures for both the police reports and victim interviews broken down by levels of public education and home visits and by study. When the data from the two studies are combined (rightmost columns), the highest rates of officially reported victimization occur in the cell that received both home visit and public education treatments. This is true for prevalence and frequency measures based on official data. It is also true for prevalence of abuse based on survey data. The only exception is frequency of new abuse based on survey data, where the highest rate was among those receiving both treatments, and the lowest rate was among those receiving a home visit but not public education.

Table 3 reports the results from the multivariate tests of the two randomly assigned treatments based upon the police records. The results are consistent across measures. In five out of six comparisons, assignment to home visit or public education treatments led to significantly greater prevalence and frequency of police reports as well as shorter times to failure. The only comparison that was not statistically significant was time to failure according to levels of public education. Nevertheless, even this comparison almost attained statistical significance $(P=$ 
Table 2. Rates of officially recorded and victim reported failure by treatment and study.

\begin{tabular}{|c|c|c|c|c|c|c|}
\hline & \multicolumn{2}{|c|}{ DVIEP } & \multicolumn{2}{|c|}{ Elder Abuse } & \multicolumn{2}{|c|}{ Both Studies } \\
\hline & \multicolumn{2}{|c|}{ Public Education } & \multicolumn{2}{|c|}{ Public Education } & \multicolumn{2}{|c|}{ Public Education } \\
\hline & No & Yes & No & Yes & No & Yes \\
\hline \multicolumn{7}{|l|}{ Prevalence of Police Reports } \\
\hline No Home Visit Grp. & $32 \%$ & $39 \%$ & $19 \%$ & $34 \%$ & $27 \%$ & $37 \%$ \\
\hline Assigned Home Visits Grp. & $37 \%$ & $45 \%$ & $39 \%$ & $36 \%$ & $38 \%$ & $41 \%$ \\
\hline \multicolumn{7}{|l|}{ Mean Frequency of } \\
\hline \multicolumn{7}{|l|}{ Police Reports } \\
\hline No Home Visit Grp. & 0.42 & 0.77 & 0.30 & 0.59 & 0.37 & 0.68 \\
\hline Assigned Home Visits Grp. & 0.90 & 1.35 & 0.82 & 0.69 & 0.86 & 1.04 \\
\hline \multicolumn{7}{|l|}{ Prevalence of Victimization } \\
\hline No Home Visit Grp. & $42 \%$ & $39 \%$ & $36 \%$ & $26 \%$ & $40 \%$ & $33 \%$ \\
\hline Assigned Home Visits Grp. & $38 \%$ & $52 \%$ & $37 \%$ & $37 \%$ & $38 \%$ & $45 \%$ \\
\hline \multicolumn{7}{|l|}{ Mean Frequency of } \\
\hline \multicolumn{7}{|l|}{ Victimization } \\
\hline No Home Visit Grp. & 6.59 & 7.15 & 5.25 & 3.53 & 5.99 & 5.48 \\
\hline Assigned Home Visits Grp. & 4.66 & 7.45 & 4.78 & 8.05 & 4.72 & 7.73 \\
\hline
\end{tabular}

Bolded values in boxes are statistically different from each other at $\mathrm{p}$-value $<0.05$.

$0.06)$ with an exponent beta of 1.25 . In addition, those assigned to the elder abuse study reported significantly lower rates of failure on average compared with those in the DVIEP experiment. The lower portion of Table 3 presents three models that include the treatment interaction effects. In these analyses, all six main effect comparisons between levels of home visits and levels of public education reach statistical significance. The interaction of the two, however, was not significant in any model, indicating that the effects of home visits and public education were additive.

Table 4 reports the results for the multivariate test of the treatment effects based upon the victim reports. Analysis of main effects presented in the top portion of the table shows significant increases in the frequency of abuse for those who were assigned to receive home visits (compared with those assigned not to receive home visits) and for those assigned to receive public education (compared with those assigned not to receive public education). Prevalence results are in the same direction but are not statistically significant. In addition, increasing age did not affect the prevalence of new abuse, but it did significantly increase the frequency of abuse.

The lower portion of Table 4 displays interaction effects. With the interaction model both treatment effects led to non-significant increases in the prevalence of victimization, and the interaction of the two treatments produced a trend toward increased abuse that was nearly significant $(P=0.09)$. 
Table 3. Rates of officially recorded failures (two-study comparison). $a$ Logistic regression, $b$ Cox's semi-parametric regression, $c$ negative binominal regression.

\begin{tabular}{|c|c|c|c|c|c|c|c|c|c|}
\hline \multirow[b]{2}{*}{ Parameter } & \multicolumn{3}{|c|}{ Prevalence (a) } & \multicolumn{3}{|c|}{ Time-to-failure (b) } & \multicolumn{3}{|c|}{ Frequency (c) } \\
\hline & $b$ & s.e. & $\operatorname{Exp}(b)$ & $b$ & s.e. & $\operatorname{Exp}(b)$ & $b$ & s.e. & $\operatorname{Exp}(b)$ \\
\hline \multicolumn{10}{|c|}{ Model I. Direct effects } \\
\hline \multicolumn{10}{|c|}{ Assigned treatment (no home visit group) } \\
\hline $\begin{array}{l}\text { Receive } \\
\text { home visits }\end{array}$ & 0.34 & 0.15 & 1.40 & 0.29 & 0.12 & 1.33 & 0.57 & 0.14 & 1.76 \\
\hline \multicolumn{10}{|c|}{ Assigned treatment (no public education) } \\
\hline $\begin{array}{l}\text { Receive } \\
\text { public education }\end{array}$ & 0.34 & 0.15 & 1.40 & 0.22 & 0.12 & 1.25 & 0.39 & 0.15 & 1.47 \\
\hline \multicolumn{10}{|l|}{ Covariates } \\
\hline \multicolumn{10}{|l|}{ Study (DVIEP) } \\
\hline Elder abuse & -0.57 & 0.22 & 0.56 & -0.41 & 0.17 & 0.66 & -0.66 & 0.18 & 0.52 \\
\hline \multicolumn{10}{|c|}{ Relationship (not married) } \\
\hline Married & 0.17 & 0.18 & 1.19 & 0.12 & 0.14 & 1.12 & -0.15 & 0.16 & 0.86 \\
\hline Missing & -0.27 & 0.37 & 0.76 & -0.25 & 0.30 & 0.78 & 0.03 & 0.19 & 1.03 \\
\hline Victim interview & -0.29 & 0.16 & 0.75 & 0.00 & 0.13 & 1.00 & -0.25 & 0.34 & 0.78 \\
\hline Victim's age & 0.01 & 0.01 & 1.01 & 0.01 & 0.01 & 1.01 & 0.01 & 0.01 & 1.01 \\
\hline Constant & -1.45 & 0.35 & 0.23 & & & & -1.18 & 0.34 & 0.31 \\
\hline Alpha & & & & & & & 1.81 & 0.46 & \\
\hline Sigma & & & & & & & 0.23 & 0.52 & \\
\hline \multicolumn{10}{|c|}{ Model II. Direct and interaction effects } \\
\hline \multicolumn{10}{|c|}{ Assigned treatment (no treatment group) } \\
\hline $\begin{array}{l}\text { Home } \\
\text { visits only }\end{array}$ & 0.51 & 0.22 & 1.66 & 0.30 & 0.12 & 1.35 & 0.81 & 0.21 & 2.24 \\
\hline $\begin{array}{l}\text { Public } \\
\text { education only }\end{array}$ & 0.35 & 0.15 & 1.42 & 0.24 & 0.12 & 1.27 & 0.64 & 0.23 & 1.90 \\
\hline $\begin{array}{l}\text { Home visits } \times \\
\text { public } \\
\text { education }\end{array}$ & -0.33 & 0.30 & 0.72 & -0.30 & 0.24 & 0.74 & -0.44 & 0.28 & 0.65 \\
\hline \multicolumn{10}{|l|}{ Study (DVIEP) } \\
\hline Elder abuse & -0.57 & 0.22 & 0.56 & -0.41 & 0.17 & 0.66 & -0.67 & 0.18 & 0.51 \\
\hline Constant & -1.45 & 0.35 & 0.23 & & & & -1.30 & 0.34 & \\
\hline Alpha & & & & & & & 1.81 & 0.46 & \\
\hline Sigma & & & & & & & 0.23 & 0.52 & \\
\hline
\end{tabular}

The models with the interaction terms also contain all the direct effects, but they are not reported here because they are already reported in the direct effects model. Coefficients in bold type are statistically significant at $P<0.05$.

\section{Three-study recidivism results}

In the three-study results we compare outcomes according to whether or not households were assigned to receive home visits. Reported in Table 5, multivariate analyses of officially recorded failure showed that those assigned to receive home visits reported new abuse sooner and reported more frequent abuse than those not assigned to receive home visits. The same was true for the prevalence measure, but 
Table 4. Rates of victimization (two-study comparison). a Logistic regression, $c$ negative binominal regression.

\begin{tabular}{|c|c|c|c|c|c|c|}
\hline \multirow[b]{2}{*}{ Parameter } & \multicolumn{3}{|c|}{ Prevalence (a) } & \multicolumn{3}{|c|}{ Frequency (c) } \\
\hline & $b$ & s.e. & $\operatorname{Exp}(b)$ & $b$ & s.e. & $\operatorname{Exp}(b)$ \\
\hline \multicolumn{7}{|l|}{ Model I. Direct effects } \\
\hline \multicolumn{7}{|c|}{ Assigned treatment (no home visit group) } \\
\hline Receive home visits & 0.25 & 0.17 & 1.28 & 0.41 & 0.11 & 1.51 \\
\hline \multicolumn{7}{|c|}{ Assigned treatment (no public education) } \\
\hline Receive public education & 0.05 & 0.17 & 1.05 & 0.43 & 0.10 & 1.54 \\
\hline \multicolumn{7}{|l|}{ Covariates } \\
\hline \multicolumn{7}{|l|}{ Study (DVIEP) } \\
\hline Elder abuse & -0.26 & 0.24 & 0.78 & -0.75 & 0.16 & 0.47 \\
\hline \multicolumn{7}{|l|}{ Relationship (not married) } \\
\hline Married & 0.34 & 0.20 & 1.41 & 0.09 & 0.12 & 1.09 \\
\hline Missing & -0.08 & 0.48 & 0.93 & -0.82 & 0.39 & 0.44 \\
\hline Victim's age & 0.00 & 0.01 & 1.00 & -0.02 & 0.00 & 0.98 \\
\hline Constant & -0.37 & 0.40 & & 1.28 & 0.24 & \\
\hline Alpha & & & & 0.08 & $\mathbf{0 . 0 3}$ & \\
\hline Sigma & & & & 1.83 & 0.07 & \\
\hline \multicolumn{7}{|c|}{ Model II. Direct and interaction effects } \\
\hline \multicolumn{7}{|c|}{ Assigned treatment (no treatment group) } \\
\hline Home visits only & 0.25 & 0.18 & 1.28 & -0.12 & 0.25 & 0.89 \\
\hline Public education only & 0.02 & 0.17 & 1.02 & -0.16 & 0.26 & 0.86 \\
\hline $\begin{array}{l}\text { Home visits } \times \\
\text { public education }\end{array}$ & 0.59 & 0.35 & 1.81 & 0.62 & 0.35 & 1.86 \\
\hline \multicolumn{7}{|l|}{ Study (DVIEP) } \\
\hline Elder abuse & -0.25 & 0.24 & 0.78 & -0.93 & 0.27 & 0.40 \\
\hline Constant & -0.36 & 0.40 & & 1.64 & 0.45 & \\
\hline Alpha & & & & 0.33 & 0.31 & \\
\hline Sigma & & & & 1.68 & 0.16 & \\
\hline
\end{tabular}

The models with the interaction terms also contain all the direct effects, but they are not reported here because they are already reported in the direct effects model. Coefficients in bold type are statistically significant at $P<0.05$

the effect attained only marginal statistical significance (beta $=0.26$, exp beta $=$ $1.29, P=0.065)$.

The lower portion of Table 5 adds an interaction term between treatment and study for each of the three outcome measures based on official data. ${ }^{3}$ In the analyses with interaction terms, those households assigned to home visits had a higher frequency of failure and shorter times to failure than did households not assigned to the home visit condition. The results for the prevalence measure were in the same direction but, as in the model above without interaction terms, did not approach statistical significance. None of the treatment by study interaction terms is significant. Also, as in the upper portion of the table, victims in the elder abuse study reported fewer failures on all three measures than did victims in the DVIEP study. 
Table 5. Rates of officially recorded failures (three-study comparison). $a$ Logistic regression, $b$ Cox's semi-parametric regression, $c$ negative binominal regression.

\begin{tabular}{|c|c|c|c|c|c|c|c|c|c|}
\hline \multirow[b]{2}{*}{ Parameter } & \multicolumn{3}{|c|}{ Prevalence (a) } & \multicolumn{3}{|c|}{ Time-to-Failure (b) } & \multicolumn{3}{|c|}{ Frequency (c) } \\
\hline & $b$ & s.e. & $\operatorname{Exp}(b)$ & $b$ & s.e. & $\operatorname{Exp}(b)$ & $b$ & s.e. & $\operatorname{Exp}(b)$ \\
\hline \multicolumn{10}{|c|}{ Model I. Direct effects } \\
\hline \multicolumn{10}{|c|}{ Assigned treatment (no home visit group) } \\
\hline $\begin{array}{l}\text { Receive } \\
\text { home visits }\end{array}$ & 0.26 & 0.14 & 1.29 & 0.24 & 0.11 & 1.27 & 0.47 & 0.13 & 1.60 \\
\hline \multicolumn{10}{|l|}{ Covariates } \\
\hline \multicolumn{10}{|l|}{ Study (DVIEP) } \\
\hline Elder abuse & -0.52 & 0.21 & 0.59 & -0.38 & 0.16 & 0.69 & -0.64 & 0.17 & 0.53 \\
\hline PSA2 & -0.49 & 0.24 & 0.62 & -0.35 & 0.20 & 0.71 & -0.76 & 0.24 & 0.47 \\
\hline \multicolumn{10}{|c|}{ Relationship (not married) } \\
\hline Married & 0.21 & 0.17 & 1.23 & 0.14 & 0.13 & 1.15 & 0.06 & 0.18 & 1.06 \\
\hline Missing & -0.58 & 0.29 & 0.56 & -0.41 & 0.25 & 0.67 & -0.47 & 0.25 & 0.62 \\
\hline $\begin{array}{l}\text { Victim } \\
\text { interview }\end{array}$ & -0.21 & 0.16 & 0.81 & 0.04 & 0.13 & 1.04 & -0.07 & 0.15 & 0.93 \\
\hline Victim's age & 0.01 & 0.01 & 1.01 & 0.01 & $\mathbf{0 . 0 0}$ & 1.01 & 0.01 & $\mathbf{0 . 0 0}$ & 1.01 \\
\hline Constant & -1.38 & 0.27 & 0.25 & & & & -0.90 & 0.28 & 0.41 \\
\hline Alpha & & & & & & & 1.85 & 0.44 & \\
\hline Sigma & & & & & & & 0.21 & 0.54 & \\
\hline \multicolumn{10}{|c|}{ Model II. Direct and interaction effects } \\
\hline \multicolumn{10}{|c|}{ Assigned treatment (no treatment group) } \\
\hline $\begin{array}{l}\text { Home visits } \times \\
\text { DVIEP }\end{array}$ & 0.17 & 0.16 & 1.19 & 0.52 & 0.20 & 1.68 & 0.59 & 0.19 & 1.80 \\
\hline $\begin{array}{l}\text { Home visits } \times \\
\text { elder abuse }\end{array}$ & 0.32 & 0.30 & 1.37 & 0.25 & 0.25 & 1.28 & -0.65 & 0.46 & 0.52 \\
\hline $\begin{array}{l}\text { Home visits } \times \\
\text { PSA2 }\end{array}$ & -0.37 & 0.42 & 0.69 & -0.33 & 0.36 & 0.72 & -0.09 & 0.28 & 0.92 \\
\hline $\begin{array}{l}\text { Time } \times \\
\text { treatment }\end{array}$ & & & & -0.33 & 0.36 & 0.72 & & & \\
\hline \multicolumn{10}{|l|}{ Study (DVIEP) } \\
\hline Elder abuse & -0.54 & 0.21 & 0.58 & -0.40 & 0.17 & 0.67 & -0.58 & 0.24 & 0.56 \\
\hline PSA2 & -0.43 & 0.24 & 0.65 & -0.29 & 0.20 & 0.75 & -0.38 & 0.38 & 0.69 \\
\hline Constant & -1.38 & 0.27 & & & & & -0.94 & 0.28 & \\
\hline Alpha & & & & & & & 1.88 & 0.44 & \\
\hline Sigma & & & & & & & 0.13 & 0.84 & \\
\hline
\end{tabular}

The models with the interaction terms also contain all the direct effects, but they are not reported here because they are already reported in the direct effects model. Coefficients in bold type are statistically significant at $P<0.05$.

Table 6 reports the analysis of prevalence of new abuse based on survey results. The proportion of victims reporting new abuse did not differ significantly according to whether victims were assigned to receive a home visit or not. Like the majority of other comparisons, however, those assigned home visits had greater odds of victimization. In fact, for both outcome measures (victim interviews and police reports), victims assigned home visits had similarly greater odds $(+29 \%$ and 
Table 6. Prevalence of victimization (three-study comparison). a Logistic regression model.

\begin{tabular}{|c|c|c|c|}
\hline \multirow[b]{2}{*}{ Parameter } & \multicolumn{3}{|c|}{ Prevalence (a) } \\
\hline & $b$ & s.e. & $\operatorname{Exp}(b)$ \\
\hline \multicolumn{4}{|l|}{ Model I. Direct effects } \\
\hline \multicolumn{4}{|c|}{ Assigned treatment (no home visit group) } \\
\hline Receive home visits & 0.25 & 0.16 & 1.28 \\
\hline \multicolumn{4}{|l|}{ Study (DVIEP) } \\
\hline Elder abuse & -0.16 & 0.24 & 0.85 \\
\hline PSA2 & -0.80 & 0.27 & 0.45 \\
\hline \multicolumn{4}{|l|}{ Covariates } \\
\hline \multicolumn{4}{|l|}{ Relationship (not married) } \\
\hline Married & 0.26 & 0.19 & 1.29 \\
\hline Missing & -0.14 & 0.48 & 0.87 \\
\hline Victim's age & -0.01 & 0.01 & 0.99 \\
\hline Constant & -0.39 & 0.36 & 0.68 \\
\hline \multicolumn{4}{|c|}{ Model II. Direct and interaction effects } \\
\hline \multicolumn{4}{|c|}{ Assigned treatment (no treatment group) } \\
\hline Home visits $\times$ DVIEP & 0.24 & 0.21 & 1.27 \\
\hline Home visits $\times$ elder abuse & 0.06 & 0.35 & 1.06 \\
\hline Home visits $\times$ PSA2 & -0.01 & 0.56 & 0.99 \\
\hline \multicolumn{4}{|l|}{ Study (DVIEP) } \\
\hline Elder abuse & -0.16 & 0.24 & 0.85 \\
\hline PSA2 & -0.80 & 0.28 & 0.45 \\
\hline Constant & -0.39 & 0.36 & 0.68 \\
\hline
\end{tabular}

The models with the interaction terms also contain all the direct effects, but they are not reported here because they are already reported in the direct effects model. Coefficients in bold type are statistically significant at $P<0.05$.

$+28 \%$ ) of failing than the control group did. In addition, those assigned to the PSA2 treatment, particularly those in the control group, had smaller odds of victimization than those assigned to the DVIEP control group.

\section{Service use results}

Across the three studies, about one in three victims received at least one service after the initiating incident, but just about $5 \%$ received more than four services. On average, each victim received about 1.5 services between the initial incident and the final victim interview.

Table 7 reports the results from a multivariate negative binomial regression model of the quantity of services received. The model on the left compares quantity of services received between those who received home visits and those who did not, across the three studies (victim relationship to abuser, victim age, and study were statistically controlled). The first model shows that the victims assigned to receive home visits only received slightly more services than those not receiving 
Table 7. Quantity of service received by the victim. a Negative binominal regression model.

\begin{tabular}{|c|c|c|c|c|c|c|}
\hline \multirow[b]{2}{*}{ Parameter } & \multicolumn{3}{|c|}{ Three Studies (a) } & \multicolumn{3}{|c|}{ Two Studies (a) } \\
\hline & $b$ & s.e. & $\operatorname{Exp}(b)$ & $b$ & s.e. & $\operatorname{Exp}(b)$ \\
\hline \multicolumn{7}{|l|}{ Model I. Direct effects } \\
\hline \multicolumn{7}{|c|}{ Assigned treatment (no home visit group) } \\
\hline Receive home Visits & 0.12 & 0.07 & 1.13 & 0.11 & 0.08 & 1.12 \\
\hline \multicolumn{7}{|c|}{ Assigned treatment (no public education) } \\
\hline Receive public education & & & & 0.05 & 0.07 & 1.05 \\
\hline \multicolumn{7}{|l|}{ Covariates } \\
\hline \multicolumn{7}{|l|}{ Study (DVIEP) } \\
\hline Elder abuse & -1.13 & 0.10 & 0.32 & -1.14 & 0.11 & 0.32 \\
\hline PSA2 & -0.28 & 0.12 & 0.76 & & & \\
\hline \multicolumn{7}{|l|}{ Relationship (not married) } \\
\hline Married & 0.11 & 0.08 & 1.12 & 0.10 & 0.08 & 1.11 \\
\hline Missing & -0.07 & 0.20 & 0.93 & -0.06 & 0.21 & 0.94 \\
\hline Victim's age & 0.00 & 0.00 & 1.00 & 0.00 & 0.00 & 1.00 \\
\hline Constant & 0.64 & 0.13 & & 0.61 & 0.14 & \\
\hline Alpha & 0.06 & 0.04 & & 0.08 & 0.05 & \\
\hline \multicolumn{7}{|c|}{ Model II. Direct and interaction effects } \\
\hline \multicolumn{7}{|c|}{ Assigned treatment (no treatment group) } \\
\hline Home visits $\times$ DVIEP & 0.05 & 0.09 & 1.05 & & & \\
\hline Home visits $\times$ elder abuse & 0.13 & 0.25 & 1.14 & & & \\
\hline Home visits $\times$ PSA2 & 0.24 & 0.16 & 1.28 & & & \\
\hline \multicolumn{7}{|c|}{ Assigned treatment (no treatment group) } \\
\hline Home visits only & & & & 0.10 & 0.11 & 1.10 \\
\hline Public education only & & & & 0.04 & 0.11 & 1.04 \\
\hline Home visits $\times$ public education & & & & 0.02 & 0.15 & 1.02 \\
\hline \multicolumn{7}{|l|}{ Study (DVIEP) } \\
\hline Elder abuse & -1.27 & 0.15 & 0.28 & -1.14 & 0.11 & 0.32 \\
\hline PSA2 & -0.36 & 0.20 & 0.70 & & & \\
\hline Constant & 0.14 & 0.39 & & 0.61 & 0.14 & \\
\hline Alpha & 0.05 & 0.04 & & 0.08 & 0.05 & \\
\hline
\end{tabular}

The models with the interaction terms also contain all the direct effects, but they are not reported because they are redundant to the direct effects model. Coefficients in bold type are statistically significant at $P<0.05$.

home visits. The model on the right, based only on the DVIEP and elder abuse data, considers whether assignment to public education adds to the quantity of services received. In this model, neither home visits or public education, nor the joint effect of both treatments, significantly increased the number of services received by the victims. Thus, there is no evidence that either of the experimental interventions increased victims' use of services.

\section{Home visit interventions received versus assigned}

The consistent higher reporting of new abuse by victims assigned to receive a home visit is, perhaps, surprising, since the intervention was brief. Moreover, not 
every household assigned to the home visit condition received personal contact from the DVIEP team: in the DVIEP study, $31 \%$ of households assigned to the home visit condition in fact received only literature because residents were not home during the two home visit attempts. In the elder abuse study, $16 \%$ received only literature.

Next, we conducted a dose-response analysis comparing recidivism rates between households where the program established personal contact through a home visit and households assigned to receive home visits that received only literature. We would expect that, if the home visit intervention was truly causing an increase in reported abuse between experimental and control households, then those households where personal contact was made should report more subsequent abuse than households where literature was left after unsuccessful home visit attempts. In five of the six comparisons, those cases assigned to the home visit condition that received personal contact reported more abuse both to police and to research interviewers than did cases in which literature was left but no personal contact was established. This was true in both studies for frequency of complaints made to the police ( 0.80 to 0.69 for the elder abuse study and 1.25 to 0.81 for the DVIEP study), in both studies for frequency/severity of abuse reports made to research interviewers (9.34 to 7.03 for the elder abuse study and 7.05 to 3.55 for the DVIEP study), and in the DVIEP study for prevalence of abuse reports made to research interviewers ( $48 \%$ to $35 \%$ ). The only exception to the pattern was for prevalence of abuse reported to research interviewers in the elder abuse study ( $41 \%$ for literature left only to $36 \%$ for actual personal contact made during home visit). Thus, we were able to confirm that a more potent "dose" of the home visit intervention was associated with higher rates of reporting of new abuse.

\section{Discussion}

The results of the re-analysis of data from three separate field experiments, testing the same interventions, consistently indicated that the interventions were associated with an increase in reporting of new abusive incidents to authorities and to research interviewers. On 14 out of 14 measures of new abuse included in the two re-analyses - both those based on official reports and those based on victim interviews - we found that those groups assigned to receive home visit or public education interventions reported more abuse than control groups did. In seven out of ten comparisons in the three-study analysis, differences between treatment levels reached statistical significance. In two of the four comparisons performed in the two-study analysis, results attained statistical significance. Because the findings are robust across the three studies, we believe increased reporting of abuse is not idiosyncratic to one of the samples but likely reflects the relationships between receiving the treatment and subsequent abuse. However, we do not know the extent to which the negative results are applicable to similar programs in other places or to populations outside public housing. 
Does more frequent reporting necessarily mean greater abuse, or could it be that persons assigned to the intervention groups become more sensitized to abuse? In the report on the elder abuse study, Davis, Medina, and Avitabile (Davis et al. 2000) presented data that argued against the sensitization hypothesis. In addition, surveys such as the National Crime Victimization Survey are widely accepted as the most accurate method of assessing the true prevalence of victimization. If we do allow for the possibility that our survey results are biased by exposure to the study interventions, then one would also have to consider that surveys like the National Crime Victimization Survey (NCVS) might be influenced by exposure to crime reports in the media or other influences. Nevertheless, in the end, we do not know for sure which alternative is correct. We did not expect to find increased reporting of abuse and so did not design the analysis to distinguish between increases in abuse and increased sensitivity to abuse. At the outset, the program logic model posited that new abuse would decline as victims extracted themselves from self-defeating relationships or worked with social services and criminal justice staff to develop strategies to end the abuse while staying in the relationship. However, we found no evidence that those who received the interventions were more likely to avail themselves of social or legal services, so the intervention could not have worked - at least not in the way intended.

There is a literature on desistance of family violence that may be useful as a lens through which to analyze these findings. This literature suggests that the typical batterer's career is either short or sporadic (Feld and Straus 1989; Maxwell et al. 2002; Langan and Innes 1986; Quigley and Leonard 1996). But for those batterers who do not quickly desist, Fagan (1989) argues that social and legal sanctions initiated by the victim might raise the personal or social costs to the batterer sufficiently to promote reduction or cessation of the abuse. The interventions we examined were designed to induce desistance by empowering women to leave the relationship, demand change under threat of leaving, or inflict shame on the abuser. For instance, the physical presence of a police officer might have directly stigmatized those abusers who were present at the time of the home visit (Maxwell 1998). But at the same time Fagan (1989) and Sherman (1992) warn that criminal sanctions may produce more abuse, especially among the chronic abusers or those with low stakes in conformity. That may have happened with our victims, since many lived in households with relatively low stakes in conformity and all lived in areas of concentrated disadvantage. It is possible that the combined interventions increased new abusive incidents by inciting abusers; however, we do not have direct evidence on this point since we did not interview abusers.

There is, however, some precedent for iatrogenic outcomes resulting from attempts to intervene with victims of intimate partner violence. For example, Ford (1991) reports results from an experiment that batterers who were prosecuted to conviction were significantly angrier than men whose cases were diverted or dropped. Another example is the research by Dugan et al. (1999) that found, after regression of the domestic homicide rates on several measures including 
availability of services for victims, that counseling services were positively correlated with homicides of both married men and unmarried women, while the presence of hotline and legal advocacy services was associated with lower homicide rates of married men. Harrell (1991) reported that a larger proportion of men assigned to batterer intervention programs committed new abuse than men assigned to a control group. Finally, Sherman (1992) reported that, among unemployed spouse abusers living in underclass areas, arrest may increase the annual frequency of reported violence (see McCord 2003) for other prevention programs found harmful.

We caution readers to consider several additional points while interpreting our work. We tested specific elements of an intervention strategy based on empowering victims. The fact that we found these elements to increase reports of new abuse does not invalidate the empowerment model. All we can say is that the follow-up home visits as they were conducted for our research increased reports of new abuse to both the police and to our interviewers. If the visits were structured differently, or had the follow-up contact used telephone or letter modalities (as is the case with Safe Horizon's program), we might have found a different pattern of results.

Some might argue against combining data from the studies at all. Although the interventions were similar, the populations and offenses were different from one study to the next. Also, one of the outcome measures (frequency/severity of abuse) was defined somewhat differently in the elder abuse study than in the other two. However, we believe that combining these studies and finding clear differences by treatment increases the generalizability of the findings. In addition, including relevant demographics and studying identity variables in the analyses should control for many inter-study differences.

Our results suggest the need for caution on the part of advocates using similar techniques until research that is more comprehensive is completed. This research should include measures of awareness of what constitutes abuse and qualitative victim interviews to attempt to tease out the difference between actual abuse and increased sensitivity. It should also rank new incidents on a severity scale to determine whether there are differences between treatment groups in both incidents and severity. Finally, this research ought to include interviews with abusers to determine how their attitudes toward victims, their emotional states, and their motivation to commit abuse might have been impacted on by the interventions. This research might be difficult to do well, because the abusers may be difficult to locate, may not consent to the interview, and may have incentives to give dishonest responses. Moreover, there are now human subject issues that need addressing, since we now have evidence that victims in such a study who receive an intervention might be at greater risk for further abuse. Nevertheless, such research could point the way forward out of the untenable position we are now in, where well-intentioned services may place victims at risk. In the end, it is important that this research occurs, in order to learn what are the most effective and responsible services possible for family violence victims. 


\section{Acknowledgements}

This research was partially supported by the National Institute of Justice, U.S. Department of Justice under grant \# 2000-WT-VX-0007. The views expressed in this article do not necessary represent the official position of the U.S. Department of Justice, the New York City Police Department, Save Horizons, the Police Foundation, Michigan State University, the University of Michigan, or the Police Executive Research Forum.

\section{Notes}

1 While the individual results of the Taylor and Davis experiment were unpublished, the Davis and Maxwell (2002) final report to the National Institute of Justice does examined these data, but within a pooled set of analyses.

2 One reviewer of an earlier draft of the paper, for example, argued that the causal mechanisms for elder abuse and intimate partner violence may be different, and that the same interventions would not be expected to work for both.

3 A test of the proportionality of the hazard rates by assigned treatment found that they were not proportional overtime. Therefore, the time-to-failure model with interaction terms adds an additional time-dependent parameter that addresses the non-proportionality problem.

\section{References}

Anderson, D., Chenery, S. \& Pease, K. (1995). Crime Detection and Prevention Series Paper 58: Biting Back: Tackling Repeat Burglary and Car crime. 1995. Home Office, Police Research Group. Retrieved from http:/www.homeoffice.gov.uk/rds/prgpdfs/ cdp58bf.pdf.

Angrist, J. D. (2005). Instrumental variables methods in experimental criminology research: What, Why, and How? Cambridge, MA: Department of Economics, Massachusetts Institute of Technology.

Angrist, J. D. \& Hahn, J. (2004). When to control for covariates? Panel, asymptotics for estimates of treatment effects. The Review of Economics and Statistics 86(1), 58-72.

Armitage, P. (1996). The design and analysis for clinical trials. In S. Ghosh \& C. R. Rao (Eds.), Design and Analysis of Experiments vol. 13 (pp. 1-30). Handbook of Statistics. Amsterdam: Elsevier.

Banyard, V. L., Williams, L. M. and Siegel, J. A. (2002). Retraumatization among adult women sexually abused in childhood: Exploratory analysis in a prospective study. Journal of Child Sexual Abuse 11(3), 19-48.

Blettner, M., Sauerbrei, W., Schlehofer, B., Scheuchenpflug, T. \& Friedenreich, C. (1999). Traditional reviews, meta-analyses and pooled analyses in epidemiology. International Journal of Epidemiology 28(1), 1-9.

Bowers, K. J., Hirschfield, A. \& Johnson, S. D. (1998). Victimization revisited: A case study of non-residential repeat burglary in Merseyside. British Journal of Criminology (London) $38(3), 429-452$ 
Bravata, D. M. \& Olkin, I. (2001). Simple pooling versus combining in meta analysis. Evaluation and the Health Profession 24(2), 218-230.

Breipohl, A., Albrecht, P., Allan, R., Asgarpoor, S., Bhavaraju, M. \& Billinton R., et al. (1995). Pooling generating unit data for improved estimates of performance indices. Transactions on Power Systems 10(4), 1912-1918.

Budd, T. (1999). Burglary of domestic dwellings: Findings from the British Crime Survey. London, UK: Home Office.

Canada Solicitor General (1988). Multiple victimization: Canadian urban victimization survey bulletin (Tech. Rep. No. 10). Ottawa: Ministry of the Solicitor General.

Collins, P. H. (1998). Fighting words: Black women and the search for justice. Minneapolis, Minn.: University of Minnesota Press.

Davis, R. C. \& Maxwell, C. D. (2002). Preventing Repeat Incidents of Family Violence: A Reanalysis of Data from Three Field Tests (Final Report Submitted to National Institute of Justice (2000-WT-VX-0007)). New York City: Vera Institute of Justice.

Davis, R. C. \& Medina, J. (2001). Results from an elder abuse prevention experiment in New York City (NIJ Research in Brief). Washington, DC: US Department of Justice, National Institute of Justice.

Davis, R. C. \& Smith, B. E. (1994a). Teaching victims crime prevention skills: Can individuals lower their risk of crime? Criminal Justice Review 19, 56-68.

Davis, R. C. \& Smith, B. E. (1994b). The effects of victim impact statements on sentencing decisions: A test in an urban setting. Justice Quarterly 11, 453-470.

Davis, R. C. \& Taylor, B. G. (1997). A proactive response to family violence: The results of randomized experiment. Criminology 35(2), 307-333.

Davis, R. C., Median, J. \& Avitabile, N. (2000). Reducing repeat incidents of elder abuse: Results of a randomized Experiment, Final Report (Final Report Submitted to the National Institute of Justice for Grant No. 95-IJ-CX-0061 No. NCJ 189086). New York City, NY: Victim Services Research (56).

Dugan, L., Nagin, D. S. \& Rosenfeld, R. (1999). Explaining the decline in intimate partner homicide. Homicide Studies 3, 187-214.

Dutton, D. G. (1995). The domestic assault of women: Psychological and Criminal Justice Perspectives. Boston, MA: Allyn and Bacon.

Ellingworth, D., Osborn, D. R., Trickett, A. \& Pease, K. (1995). Lifestyle and prior victimization: A logit analysis of crime risk. Quantitative Criminology Group, Manchester, UK.

Fagan, J. A. (1989). Cessation of family violence: Deterrence and dissuasion. In L. Ohlin \& M. Tonry (Eds.), Family Violence vol. 11 (pp. 377-425). Crime and Justice: A Review of Research. Chicago: University of Chicago Press.

Farrell, G. (1995). Preventing repeat victimization. In M. Tonry \& D. P. Farrington (Eds.), Building a safer society: Strategic approaches to crime prevention (pp. 468-534). Crime and justice: A review of research, 19. Chicago, IL: The University of Chicago Press.

Farrell, G. \& Buckley, A. (1999). Evaluation of a UK police domestic violence unit using repeat victimization as a performance indicator. The Howard Journal 38(1), 42-53.

Farrell, G. \& Pease, K. (1993). Once bitten, twice bitten: Repeat victimization and its implications for crime prevention (Crime Prevention Unit Paper No. 46). London, UK: Home Office.

Farrell, G., Hobbs, L., Edmonds, A. \& Laycock, G. (2000). RV snapshot: UK policing and repeat victimisation. London, UK: Home Office.

Farrington, D. P. (1987). Early precursors of frequent offending. In J. Q. Wilson \& G. C. Loury (Eds.), Families, Schools, and Delinquency Prevention vol. III (pp. 27-50). From Children to Citizens. New York, NY: Springer. 
Feld, S. L. \& Straus, M. A. (1989). Escalation and desistance of wife assault in marriage. Criminology 27(1), 141-161.

Ford, D. A. (1991). Prosecution as a victim power source: A note on empowering women in violent conjugal relationships. Law and Society Review 25, 313-334.

Gabor, T., \& Mata, F. (2004). Victimization and repeat victimization over the life span: A predictive study and implications for policy. International Review of Victimilogy 10(3), 193-221.

Gartin, P. R. (1995). Dealing with design failures in randomized field experiments: Analytic issues regarding the evaluation of treatment effects. Journal of Research in Crime and Delinquency 32(4), 425-445.

Gelber, R.D., \& Zelen, M. (1986). Planning and reporting of clinical trials. In P. Calabresi, P. S. Schein \& S. A. Rosenberg (Eds.), Medical oncology (pp. 406-425). New York, NY: Macmillian Publishing Company.

Gold, S. R., Sinclair, B. B., \& Balge, K. A. (1999). Risk of sexual revictimization: A theoretical model. Aggression and Violent Behavior 4(4), 457-470.

Hall, J. A., Tickle-Degnen, L., Rosenthal, R., \& Mosteller, F. (1994). Hypotheses and problems in research synthesis. In H. Copper \& L. V. Hedges (Eds.), The Handbook of Research Synthesis (pp. 17-28). New York: Russell Sage Foundation.

Harrell, A. (1991). Evaluation of court-ordered treatment for domestic violence offenders (Final Report Supported by the State Justice Institute (\#90-121-E-089), Under Subcontract from the Institute for Social Analysis). Washington, DC: Urban Institute.

Harris, L., and Associates. (1979). A Survey of Spousal Abuse Against Women in Kentucky. New York: Harris and Associates.

Hart, B. (1992). State codes on domestic violence: Analysis, commentary, and recommendations. Reno, NV: National Council of Juvenile and Family Court Judges.

Hindelang, M., Gottfredson, M., \& Garafolo, J. (1978). Victims of personal crime: An empirical foundation for a theory of personal victimization. Cambridge, MA: Ballinger Publishing Company.

Holland, P. W. (1986). Statistics and causal inference. Journal of the American Statistical Association 81, 945-970.

Kelly, L., Bindel, J., \& Burton, S. (1999). Domestic violence matters: An evaluation of a development project. (Research Findings No. 91). London, UK: Home Office.

Lane, E., Lucera, J., \& Boba, R. (2002). Office of Community Oriented Policing Services Community Policing/Domestic Violence Test Site Project: Inter-agency response to domestic violence in a medium sized city (Prepared for the U.S. Department of Justice's Office of Community Oriented Police Services for Grant No. 98DVWXK015). Washington, DC: Police Foundation (91).

Langan, P. A., \& Innes, C. A. (1986). Preventing Domestic Violence against Women (Special Report). Washington, DC: U.S. Government Printing Office.

Laub, J. H., \& Sampson, R. J. (2001). Understanding desistance from crime. In M. Tonry (Ed.), Crime and Justice: A Review of Research vol. 28 (pp. 1-69). Chicago, IL: The University of Chicago Press.

Lauritsen, J. L., \& Davis-Quinet, K. F. (1995). Repeat victimization among adolescents and young adults. Journal of Quantitative Criminology 11, 143-166.

Litton, R. A. (2000). Criminological research and the insurance industry. Security Journal 13(2), 31-48.

Lloyd, S., Farrell, G., \& Pease, K. (1994). Preventing repeated domestic violence: A demonstration project on Merseyside (Crime Prevention Unit Paper, Police Research Group No. 49). London, UK: Home Office (28). 
Maxwell, C. D. (1998). The specific deterrent effect of arrest on aggression between intimates and spouses. Doctoral dissertation, Rutgers, the State University of New Jersey, Newark, New Jersey.

Maxwell, C. D., Garner, J.H., \& Fagan, J. A. (2002). Research, policy and theory: The preventive effects of arrest on intimate partner violence. Criminology and Public Policy 2(1), 51-80.

McCord, J. (2003). Cures that harm: Unanticipated outcomes of crime prevention program. In D. Weisburd, A. Petrosion, \& C. M. Lum (Eds.), The Annals of the American Academy of Political and Social Science [Special issue]. Assessing Systematic Evidence in Crime and Justice: Methodological Concerns and Empirical Outcomes 587, 16-30.

Menard, S. (2000). The 'normality' of repeat victimization from adolescence through early adulthood. Justice Quarterly 17(3), 543-574.

Messman-Moore, T. L., \& Long, P. J. (2000). Child sexual abuse and revictimization in the form of adult sexual abuse, adult physical abuse, and adult psychological maltreatment. Journal of Interpersonal Violence 15(5), 489-502.

Muehlenhard, C. L., Highby, B. J., \& Lee, R. S., et al. (1998). The sexual revictimization of women and men sexually abused as children: A review of the literature. Annual Review of Sex Research 9, 177-223.

National Board for Crime Prevention. (1994). Wise after the event: tackling repeat victimization. London, UK: Home Office.

Pagelow, M. D. (1981). Women-battering: Victims and their experiences. Beverly Hills, CA: Sage Publications.

Pease, K. (1998). Repeat victimization: Taking stock (Crime Detection and Prevention Series No. Paper 90). London, UK: Home Office (48).

Pease, K., \& Laycock, G. (1996). Revictimization: reducing the heat on hot victims. Washington DC: US Department of Justice, National Institute of Justice.

Pillemer, K. A., \& Finkelhor, D. (1998). The prevalence of elder abuse: A random sample survey. The Gerontologist 28(1), 51-57.

Quigley, B. M., \& Leonard, K. E. (1996). Desistance of husband aggression in the early years of marriage. Violence and Victims 11(4), 355-370.

Robinson, M. B. (1998). Burglary revictimization: The time period of heightened risk. British Journal of Criminology 38(1), 78-87.

Rubin, D. B. (1974). Estimating causal effects of treatments inrandomized and nonrandomized studies. Journal of Educational Psychology 66, 688-701.

Shaw, M., \& Pease, K. (2000). Research on repeat victimization in Scotland (Final Report). Edinburgh: Scottish Executive Central Research Unit.

Sherman, L. W. (1992). Policing domestic violence: Experiments and dilemmas. New York: Free Press.

Sorenson, S. B., Siegel, J. M., Golding, J. M., \& Stein, J. A. (1991). Repeat sexual victimization. Violence and Victims 6(4), 299-301.

Sparks, R. F. (1981). Multiple victimization: Evidence, theory, and future research. Journal of Criminal Law and Criminology 72, 762-778.

Straus, M. (1979). Measuring intrafamily conflict and violence: The conflict tactics scale. Journal of Marriage and the Family 41, 75-88.

Straus, M. A., \& Gelles, R. J. (Editors). (1990). Physical violence in American families: Risk factors and adaptations to violence in 8,145 families. New Brunswick, NJ: Transaction Press.

Taioli, E., \& Bonassi, S. (2002). Methodological issues in pooled analysis of biomarker studies. Mutat Res 512(1), 85-92. 
Tolman, R., \& Weisz, A. (1995). Coordinated community intervention for domestic violence: The effects of arrest and prosecution on recidivism of woman abuse perpetrators. Crime and Delinquency 41(4), 481-495.

Trickett, A., Osborne, D., Seymour, J., \& Pease, K. (1992). What is different about high crime areas? British Journal of Criminology 32, 81-90.

Walker, L. E. (1979). The battered women. New York: Harper and Row.

Weisel, D. L., Clarke, R. V., \& Stedman, J. R. (1999). Final Report submitted to the National Institute of Justice for grant no 96-IJ-CX-0042 (Tech. Rep. No. NCJ 193808). Washington, DC: Police Executive Research Forum (PERF) (171).

Weisz, A. N., Canales-Portalatin, D., \& Nahan, N. (2004). Evaluating a victim advocacy within a team approach. In B. Fisher (Ed.), Violence Against Women and Family Violence: Developments in Research, Practice, and Policy vol. NCJ 199718 (pp. 3(1-8)). Washington, DC: National Institute of Justice, U.S. Department of Justice.

Whitehead, P., \& Gray, P. (1998). Pulling the plug on computer theft (Police Research Series Paper No. 101). London, UK: Home Office.

Wilt, G. M., Bannon, J. D., Breedlove, R. K., Sandker, D. M., Sawtell, R. K., \& Kennish, J. W. (1977). Domestic violence and the police: Studies in Detroit and Kansas City. Police Foundation.

\section{About the authors}

Robert C. Davis is Research Director of the Police Foundation in Washington, DC. He has directed more than 30 projects on policing, domestic violence, victimization, crime prevention and prosecution for federal and state governments, and private foundations. His interests include police accountability, surveys to measure the quality of citizen experiences with the police, reducing repeat domestic violence, private policing, and victim experiences in the criminal justice system. He is the author of two books on crime prevention and editor of three books on crime prevention and crime victims.

Christopher D. Maxwell is Associate Professor in the School of Criminal Justice at Michigan State University and is Associate Research Scientist in the Inter-University Consortium for Political and Social Research at the University of Michigan, where he directs the National Archive of Criminal Justice Data. Dr. Maxwell's research interests include testing for the benefits and costs of sanctions and therapeutic treatments for spouse abusers, the impacts of police and court services on victims of domestic violence, the epidemiology of violence against women by intimates, and the extent and correlates of sexual assault by and against adolescents. His research has been supported by the Centers for Disease Control and Prevention, the National Institute of Justice, the Bureau of Justice Statistics, the H.F. Guggenheim Foundation, and the State of Michigan. He has published articles in several referred journals, including Criminology, Criminology and Public Police, Justice Quarterly and Journal of Quantitative Criminology. Dr. Maxwell earned B.A. degrees in psychology, sociology and criminal justice from Indiana University-Bloomington (1990), and M.A. (1994) and Ph.D. (1998) degrees in criminal justice from Rutgers University. 
Bruce Taylor, Ph.D., is Director of Research for the Police Executive Research Forum (PERF). Dr. Taylor has conducted studies in the areas of law enforcement, treatment for violent offenders, domestic violence, victim assistance programs, psychological effects of victimization, dynamics of drug markets, hardcore drug use, and prisoner re-entry. His research has been supported by the Bureau of Justice Assistance (BJA); Children's Bureau / ACYF/ACF/HHS; National Institute of Justice; National Institute of Mental Health; New York City Mayor's Office; Office of Community Oriented Policing Services (COPS); Office of Juvenile Justice and Delinquency Prevention, Pennsylvania Coalition Against Rape (PCAR); State of California, Department of Justice, Crime and Violence Prevention Center; and U.S. Department of Education, Institute of Education Sciences. His peer-reviewed research has been published in Addiction Biology, American Journal of Drug and Alcohol Abuse, Criminal Justice: An International Journal of Policy and Practice, Criminology, Criminology and Public Policy, Forensic Science International, Journal of Drug Issues, Journal of Personality and Social Psychology, Justice Quarterly, The Journal for the Scientific Study of Religion, Perspectives, Violence and Victims, and Women and Criminal Justice. Dr. Taylor earned a B.S. from St. John's University (1990), and M.A. (1994) and Ph.D. (1996) degrees in criminal justice from Rutgers University. 